\title{
Telepharmacy: a pharmacist's perspective on the clinical benefits and challenges [Corrigendum]
}

Poudel A, Nissen LM. Integr Pharm Res Pract. 2016;5:75-82.

On page 81 , please note reference number 32 was missing from the References section.

32. Traynor K. Remote technician supervision up and running in Kansas. Am J Health Syst Pharm. 2012;69(4):273-274. management system is completely online and includes a very quick and fair macy practice with particular focus on integrated care. All papers are carefully 